\title{
СРАВНИТЕЛЬНАЯ ОЦЕНКА ЭКОНОМИЧЕСКОГО ОБОСНОВАНИЯ И ЭФФЕКТИВНОСТИ ИЗГОТОВЛЕНИЯ ПОЛНЫХ СЬЕМНЫХ ПЛАСТИНОЧНЫХ ПРОТЕЗОВ, ПОЛУЧЕННЫХ С ПОМОЩЬЮ ТРАДИЦИОННЫХ И ЗD ТЕХНОЛОГИЙ
}

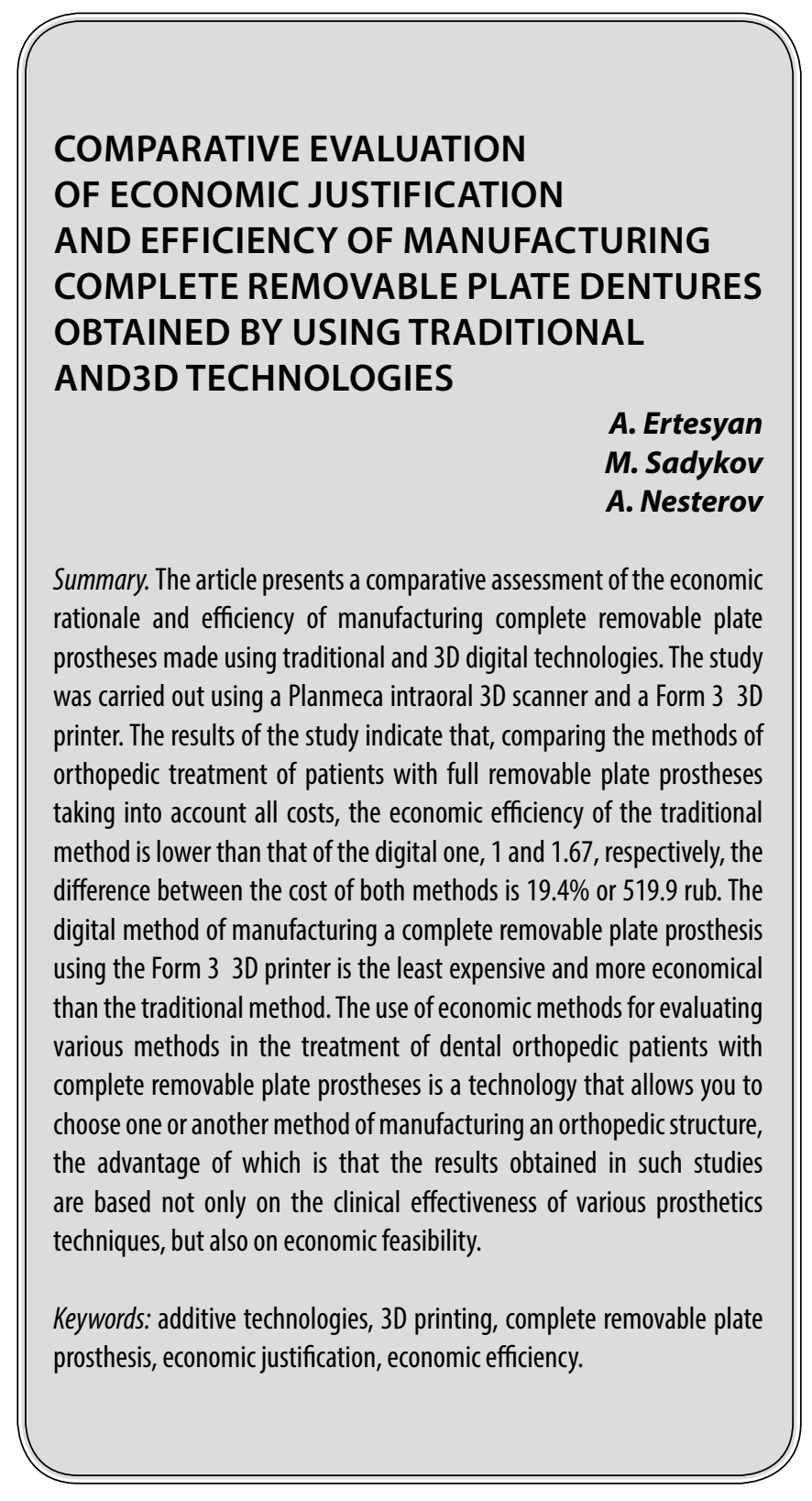

$\mathbf{H}$ а сегодняшний день существует два метода изготовления полных съемных пластиночных протезов в зависимости от того, кем и как изготавливается протез - врачом стоматологом-ортопедом (цифровой метод), либо врачом стоматологом-ортопедом и зубным

\author{
Эртесян Альберт Робертович \\ К.м.н., ассистент, ФГБОУ ВО «Самарский \\ государственный медицинский университет» \\ Минздрава России, Самара \\ albertertesyan@gmail.com \\ Садыков Мукатдес Ибрагимович \\ Д.м.н., профессор, ФГБОУ ВО «Самарский \\ государственный медицинский университет» \\ Минздрава России, Самара \\ Нестеров Александр Михайлович \\ Д.м.н., професссор, ФГБОУВО «Самарский \\ государственный медичинский университет» \\ Минздрава России, Самара
}

Аннотация. В статье представлена сравнительная оценка экономического обоснования и эффективности изготовления полных съемных пластиночных протезов, выполненных с помощью традиционных и 3D цифровых технологий. Для проведения исследования использовали интраоральный 3D сканер Planmeca и 3D принтер Form 3. Результаты исследования свидетельствуют о том, сравнивая методы ортопедического лечения пациентов полными съемными пластиночными протезами с учетом всех затрат, экономическая эффективность традиционного метода ниже, чем цифрового, 1 и 1,67 соответственно, разница между стоимостью обеих методов составляет 19,4\% или 519,9 руб. Цифровой метод изготовления полного съемного пластиночного протеза с применением 3D принтера Form 3 наименее затратный и экономически более выгодный по сравнению с традиционным методом. Применение экономических методов оценки различных методов в лечении стоматологических ортопедических пациентов полными съемными пластиночными протезами представляет собой технологию, позволяющую выбрать тот или иной метод изготовления ортопедической конструкции, преимущество которого заключается в том, что результаты, полученные в таких исследованиях, основаны не только на клинической эффективности различных методик протезирования, но и на экономической целесообразности.

Ключевые слова: аддитивные технологии, 3D печать, полный съемный пластиночный протез, экономическое обоснование, экономическая эффективHость.

техником (лабораторный метод). В клинических условиях врач может получить полный съемный пластиночный протез из фотополимерных смол, применяя методику 3D печати $[4,9]$. Цифровой метод основан на получении виртуальных изображений $[1,3]$, компьютерном модели- 
ровании и изготовлении полных съемных пластиночных протезов с помощью 3D принтеров [10]. Лабораторный метод изготовления полных съемных пластиночных протезов выделяют в традиционный метод. Научных публикаций, посвященных сравнительной оценке экономического обоснования изготовления полных съемных пластиночных протезов крайне мало, что и явилось обоснованием для проведения данного исследования.

\section{Цель исследования}

Провести сравнительную оценку экономического обоснования и эффективности изготовления полных съемных пластиночных протезов, полученных с помощью традиционных и 3D методов.

\section{Материалы и методы исследования}

Разные технологии изготовления полных съемных пластиночных протезов предполагают и разные затраты, что важно для экономического обоснования применяемых методов изготовления полных съемных пластиночных протезов.

Как известно, расчет себестоимости медицинской услуги (C) осуществляется по формуле [6]:

$$
\mathrm{C}=\mathrm{C} n+\mathrm{CK}_{\mathrm{H}}=3 \mathrm{~T}+\mathrm{H}_{3}+\mathrm{M}+\mathrm{U}+\mathrm{O}+\Pi,
$$

где: Сп - прямые расходы; Ск - косвенные расходы; 3т - расходы на оплату труда; Н3 - начисления на оплату труда; М - расходы на медикаменты, перевязочные средства и пр.; И - износ мягкого инвентаря; О — износ оборудования; П- прочие расходы.

Вне зависимости от метода изготовления полных съемных пластиночных протезов расходы на оплату труда, начисления на оплату труда, косвенные расходы, в том числе расходы на коммунальные услуги будут одинаковыми. Соответственно разница в стоимости услуги изготовления полного съемного пластиночного протеза с применением традиционных и 3D технологий определяется, в первую очередь, расходами на материалы и износом (амортизацией) инструментов и оборудования, применяемых в том или ином методе изготовления съемного протеза $[2,6]$.

Стоимость затрат (C) на расходные материалы рассчитывается по следующей формуле:

$$
C=Ц / M^{*} H P \text {, }
$$

где: Ц - рыночная цена расходного материала; М масса материала в упаковке; НР - норма расхода материала для изготовления съемного протеза.
Нормы расхода материалов зуботехнические лаборатории и стоматологические клиники могут устанавливать самостоятельно в зависимости от фактического расхода используемых материалов. Также в некоторых литературных источниках приводятся усредненные нормы расхода стоматологических материалов [11], которые носят рекомендательный характер.

Амортизация (А) медицинского оборудования рассчитывалась по следующей формуле:

$$
\mathrm{A}=Ц / M
$$

где: Ц - рыночная цена оборудования; И - срок полезного использования в расчете на УЕТ.

Стоматологическое оборудование относится к 4-й амортизационной группе со сроком полезного использования от 5 лет (60 мес.) до 7 лет (84 мес.) включительно [7]. Изготовление ПСПП лабораторным методом соответствует 6,6 УЕТ, цифровым способом - 4 УЕТ [6]. 1 УЕТ - это 20 минут рабочего времени специалиста [8]. Таким образом, срок полезного использования в расчете на УЕТ можно рассчитать по следующей формуле:

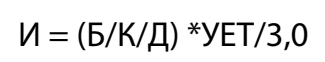

где: Б - срок полезного использования оборудования в мес.; К - количество рабочих дней в месяце (21); Д-количество рабочих часов специалиста в день (для стоматолога ортопеда и зубного техника 6,6 ч.).

Для точной оценки эффективности различных методов ортопедического лечения была применена методика, предложенная А.Г. Лукиным, А.Р. Сараевым (2020), названная ими «эталонным подходом» к измерению эффективности оказания медицинской услуги [5]. Сущность данного подхода заключается в том, что на основании медицинских наблюдений выбирается наиболее действенная методика лечения конкретного заболевания, дающее возможность наиболее быстро достигнуть нужного клинического результата, которая принимается за эталон. В качестве постулата принимается, что экономическая эффективность данной методики (назовем ее эталонной) лечения равна 1, т.е. затраты на ее применение выражают её экономический результат:

\section{Результат 1 / Затраты 1 = Эффективность 1}

Если необходимо измерить эффективность другой методики лечения данного заболевания, то затраты на её реализацию сравнивают с результатом эталонной (первой) методики:

Результат 1 / Затраты 2 = Эффективность 2 
Таблица 1. Стоимость затрат на расходные материалы для изготовления полного съемного пластиночного протеза в зависимости от метода изготовления

\begin{tabular}{|c|c|c|c|}
\hline Метод изготовления ПСПП & Наименование материалов & Кол -во & $\begin{array}{l}\text { Стоимость затрат, } \\
\text { ру6. }\end{array}$ \\
\hline \multirow{13}{*}{ Традиционный метод } & Альгинатный материал «Ypeen» & 80 гр. & 40,5 \\
\hline & Корригирующий слой «Speedex» & 18 мл. & 92,5 \\
\hline & Активатор «Speedex» & 7,5 мл. & 119,3 \\
\hline & Гипс медицинский (все этапы) & 250 гр. & 5,00 \\
\hline & Индивидуальной ложки «Megatray» & 1 шт. & 78,6 \\
\hline & Воск базисный «Беловакс» (все этапы) & 40 гр. & 39,2 \\
\hline & Зубы искусственные «ҮАМАНАСНl» & 14 шт. & 450,00 \\
\hline & Лак разделительный зуботехнический & 15 мл. & 15,84 \\
\hline & Пластмасса базисная «Basis» & 30,8 гр. & 90,6 \\
\hline & Фрезы зуботехнические & 0,05 & 15,6 \\
\hline & Полир головки, фильцы, паста и т.д. & 0,05 & 15,2 \\
\hline & Бахилы, перчатки, маска, нагрудник & 5 комп. & 223,00 \\
\hline & \multicolumn{2}{|l|}{ ИТОГО: } & 1185,3 \\
\hline \multirow{4}{*}{ Цифровой метод } & Denture Base Resin & 21 мл. & 333,9 \\
\hline & Denture Teeth Resin & 17 мл. & 232,9 \\
\hline & Бахилы, перчатки, маска, нагрудник & 1 комп & 44,6 \\
\hline & \multicolumn{2}{|l|}{ итого: } & 611,4 \\
\hline
\end{tabular}

Таблица 2. Стоимость затрат на амортизацию оборудования, необходимого для изготовления полного съемного пластиночного протеза в зависимости от метода изготовления

\begin{tabular}{|c|c|c|c|c|c|}
\hline $\begin{array}{l}\text { Метод изготовления } \\
\text { ПСПП }\end{array}$ & $\begin{array}{l}\text { Медицинская техника, } \\
\text { инструментарий }\end{array}$ & Цена, руб. & $\begin{array}{l}\text { Срок полезного } \\
\text { использования мес. }\end{array}$ & YET & $\begin{array}{l}\text { Амортизация } \\
\text { руб. за УЕТ }\end{array}$ \\
\hline \multirow{7}{*}{ Традиционный метод } & Оттискная ложка & 800 & 84 & 6,6 & 0,15 \\
\hline & Кювета & 8000 & 84 & 6,6 & 1,21 \\
\hline & Артикулятор & 9574 & 84 & 6,6 & 1,80 \\
\hline & «ПВА 1.0 АРТ» & 39500 & 84 & 6,6 & 7,42 \\
\hline & «ПОЛИР 6.3 МАСТЕР» & 23000 & 84 & 6,6 & 4,34 \\
\hline & $\begin{array}{l}\text { Стоматологическая } \\
\text { установка }\end{array}$ & 470000 & 84 & 6,6 & 88,8 \\
\hline & \multicolumn{4}{|l|}{ итОГО: } & 103,7 \\
\hline \multirow{4}{*}{ Цифровой метод } & Сканер «Planmeca» & 960000 & 84 & 4 & 109,92 \\
\hline & 3D принтер «Form 3» & 350000 & 84 & 4 & 40,08 \\
\hline & Wash and Cure & 12000 & 84 & 4 & 2,7 \\
\hline & \multicolumn{4}{|l|}{ итого: } & 157,7 \\
\hline
\end{tabular}

Таблица 3. Стоимость затрат на расходные материалы и амортизацию оборудования для полного съемного пластиночного протеза в зависимости от метода изготовления

\begin{tabular}{|l|l|l|l|}
\hline Метод изготовления ПСПП & $\begin{array}{l}\text { Затраты на расходные } \\
\text { материалы }\end{array}$ & $\begin{array}{l}\text { Затраты на амортизацию } \\
\text { оборудования }\end{array}$ & итого \\
\hline Традиционный метод & 1185,3 & 103,7 & 1289,0 \\
\hline Цифровой метод & 611,4 & 157,7 & 769,1 \\
\hline
\end{tabular}


Экономически более эффективная методика лечения будет измеряться коэффициентом больше единицы, так как заданный результат достигается при меньших затратах и наоборот при значении эффективности меньше единицы эталонная методика предпочтительнее. Применение эталонного подхода возможно только при достижении одинакового результата.

\section{Результаты исслеАования}

Некоторые расходные материалы используются при изготовлении полного съемного пластиночного протеза вне зависимости от технологии изготовления (перчатки, маски, шапочки, нагрудники, пакеты для стерилизации инструментов и др.). Однако существуют расходные материалы, применение которых обусловлено методом изготовления полного съемного пластиночного протеза. Именно стоимость таких материалов особенно будет влиять на различия в стоимости услуг по изготовлению полного съемного пластиночного протеза различными методами (таблица 1).

Часть стоматологического материала и инструментов используется при изготовлении полного съемного пластиночного протеза вне зависимости от метода изготовления. Однако есть оборудование, применение которого обусловлено методом изготовления полного схемного пластиночного протеза, именно затраты на амортизацию этого оборудования будут влиять на различия в стоимости услуг по изготовлению полного съемного пластиночного протеза различными методами (таблица 2).

В таблице 3 представлены затраты на расходные материалы и амортизацию оборудования, необходимых для изготовления полного съемного пластиночного протеза, затраты на которые будут различны в зависимости от метода изготовления.

Совокупные затраты на ортопедическое лечение полными съемными пластиночными протезами по тра- диционному методу составляют 1289,0 руб., а коэффициент финансовой эффективности 1.

Стоимость затрат на изготовление полных съемных пластиночных протезов по цифровому методу составили 769,1 руб., коэффициент финансовой эффективности 1,67 .

\section{Зак^ючение}

Таким образом, сравнивая методы ортопедического лечения пациентов полными съемными пластиночными протезами с учетом всех затрат, экономическая эффективность традиционного метода ниже, чем цифрового, 1 и 1,67 соответственно, разница между стоимостью обеих методов составляет 19,4\% или 519,9 руб. Цифровой метод изготовления полного съемного пластиночного протеза с применением 3D принтера Form 3 наименее затратный и экономически более выгодный по сравнению с традиционным методом.

Применение экономических методов оценки различных методов в лечении стоматологических ортопедических пациентов полными съемными пластиночными протезами представляет собой технологию, позволяющую выбрать тот или иной метод изготовления ортопедической конструкции, преимущество которого заключается в том, что результаты, полученные в таких исследованиях, основаны не только на клинической эффективности различных методик протезирования, но и на экономической целесообразности.

Рассматривая всех больных нуждающихся в таком виде ортопедического лечения можно получить значительный экономический эффект, с учетом их доли в общем потоке ортопедических пациентов. Это приведет к снижению затрат пациента с указанной патологией на протезирование полными съемными пластиночными протезами, снижению затрат стоматологических служб и сокращению нагрузки на медицинский персонал.

\section{ЛИТЕРАТУРА}

1. Вокулова Ю.А., Жулев Е. Н. Оценка точности получения оттисков зубных рядов с применением технологии лазерного сканирования // Современные проблемы науки и образования.— 2016. — № 5. — C. 164. URL: http://www.science-education.ru/ru/article/view?id=25447.

2. Гиннятулина Р.И. Международные подходы к управлению качеством медицинской помощи (обзор литературы) // Наука и инновации в медицине.2019.— № 4(4). C. 38-43. doi: 10.35693/2500-1388-2019-4-4-38-43

3. Жулев Е.Н., Вокулова Ю. А. Изучение размерной точности цифровых оттисков, полученных с помощью внутриротового сканера іТего // Международный журнал прикладных и фундаментальных исследований. — 2016. — № 12-2.— C. 257-261. URL: https://applied-research.ru/ru/article/view?id=10818.

4. Петрова Н.Г., Погосян С. Г. Мотивация медицинского персонала как важный элемент кадрового менеджмента. Наука и инновации в медицине.2020. — No 5(2). — C. 105-110. doi: 10.35693/2500-1388-2020-5-2-105-110

5. Лукин А.Г., Сараев А.Р., Измайлов А. М. Ещё раз к вопросу об экономической эффективности медицинской услуги // Экономика и предпринимательСтв0. - 2020.— № 8 (121). С. 1162-1165 
6. Инструкция по расчету стоимости медицинских услуг (временная) / (утв. Минздравом РФ N01-23/4-10, PAMH N01-02/41 10.11.1999). http://www. consultant.ru/cons/cgi/online.cgi?req $=$ doc\&base $=E X P \& n=290985 \# 0284366150799069$

7. Постановление Правительства РФ от 01.01.2002 N1 (ред. от 27.12.2019) «0 Классификации основных средств, включаемых в амортизационные группы». http://www.consultant.ru/document/cons_doc_LAW_34710/

8. Приказ Минздрава РФ от 15.11.2001 N408 «0б утверждении Инструкции по расчету условных единиц трудоемкости работы врачей-стоматологов и зубных врачей». http://www.consultant.ru/cons/cgi/online.cgi?req=doc\&base=EXP\&n=267258\#0576083111313946

9. Путеводитель по стоматологии ортопедической (Стоматологическая поликлиника) / В. Д. Вагнер, В. М. Семенюк, О. В. Чекунков.- М.: Мед. кн.; Н. Новгород: НГМА, — 2004. — (ПИК ВИНИТИ). — 579 с.

10. Шустова В.А., Шустов М. А. Применение 3D-технологий в ортопедической стоматологии. Санкт-Петербург: СпецЛит; - 2016. - 159 с.

11. e-Stomatology.ru. Официальный сайт Стоматологической Ассоциации России.

○ Эртесян Альберт Робертович ( albertertesyan@gmail.com ), Садыков Мукатдес Ибрагимович, Нестеров Александр Михайлович.

Журнал «Современная наука: актуальные проблемы теории и практики»

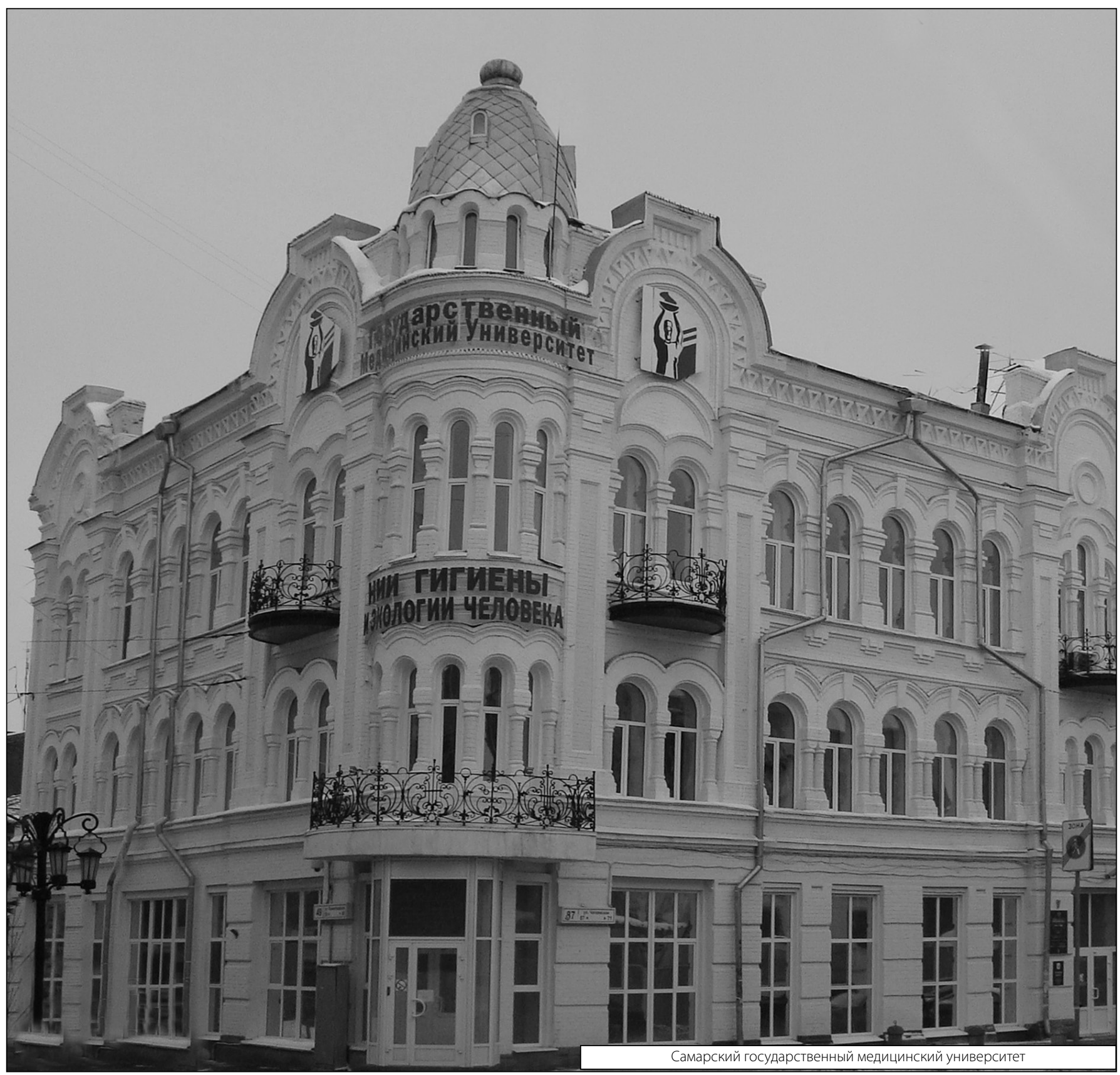

